\title{
|||||||||||||||||||||||||||||||||||||||||||||||||||||||||||||||||||.
}

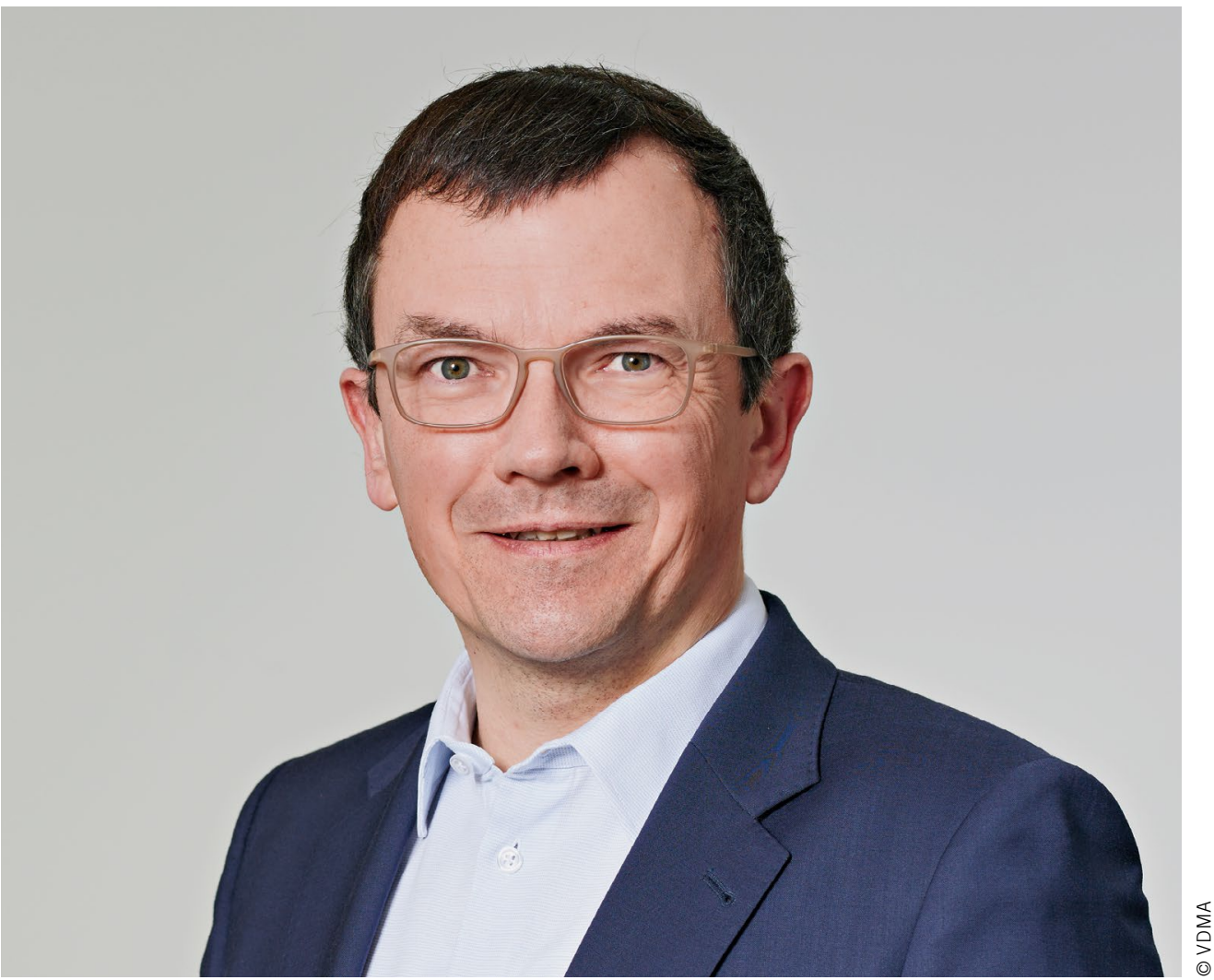

Peter Müller-Baum Geschäftsführer VDMA Motoren und Systeme, Power-to-X Applications und CIMAC Generalsekretär

\section{Runter vom hohen Ross}

Manchmal frage ich mich, wie der vor etwa 100 Jahren stattgefundene Wandel im Straßenbild von Pferdedroschken hin zu Automobilen in unserer heutigen Welt mit sozialen Medien und häufigen Simplifizierungen kommentiert würde: Gäbe es da auch die Fraktion, die nicht müde würde, darauf hinzuweisen, dass es nicht genügend Tankstellen geben könne, um die Automobile permanent mit Sprit zu versorgen? Und auf der anderen Seite diejenigen, die dringend Pferdedroschken verbieten wollen, da Automobile nun einmal viel effizienter seien?

Ja, natürlich hinkt dieser Vergleich - aber mir kommt diese ständige „Entweder-oder“-Debatte dennoch ähnlich absurd vor. Ist es nicht offensichtlich, dass batterieelektrische Fahrzeuge langfristig - das heißt in einer defossilisierten Welt - ihre Vorteile wie Effizienz und, ja, später auch Kosten, in verschiedenen Anwendungen ausspielen können? Dass es gleichwohl Bereiche gibt, in denen nicht nur die Physik, sondern auch ökonomische Aspekte dagegensprechen, ausschließlich auf eine Technologie zu setzen? In der Luft- und Schifffahrt, in Teilen des Schwerlastverkehrs und bei mobile Maschinen, und in der riesigen Bestandsflotte weltweit nämlich. In manchen Regionen der Welt sieht man übrigens auch heute noch völlig selbstverständlich Pferdekutschen auf den Straßen.
Für die Großmotorenindustrie lassen sich diese Fragen recht einfach (und größtenteils unstrittig) beantworten - problematisch ist hier aber, dass ein solch massiver Wandel der Mobilität, wie wir ihn wohl derzeit am Horizont erahnen können, natürlich immense Auswirkungen auf die gesamten Wertschöpfungsketten inklusive des akademischen Umfelds haben wird. Sprich: Falls in Europa keinerlei Verbrennungsmotoren für die Straße mehr gebaut werden, gibt es dann hier noch das notwendige Know-how für die Großmotorenindustrie? Wie sieht die Zulieferindustrie künftig aus? Wie die Welt der Forschung?

All dies sind komplexe Fragen, die sich hier nicht beantworten lassen, zumal die Wechselwirkungen mit künftigen Energiesystemen und Welthandelsströmen ja noch nicht einmal angerissen wurden. Meine Hoffnung wäre jedoch, dass wir es schaffen, die Diskussion zu versachlichen. Denn während der beginnende Wandel meines Erachtens (und zu Recht) unaufhaltsam ist, sind die damit verbundenen Herausforderungen nur gemeinsam so lösbar, dass damit nicht schwerwiegende Wohlstandsverluste einhergehen. Eine von Polemik möglichst unberührte Debatte wäre notwendig bei der weiteren Entwicklung praxistauglicher und akzeptabler Lösungswege weltweit. 